\title{
Processamento de Laminados de Compósitos Poliméricos Avançados com Bordas Moldadas
}

\author{
Geraldo M. Cândido e Sérgio F. M. Almeida \\ Instituto Tecnológico de Aeronáutica , Divisão de Engenharia Mecânica Aeronáutica
}

\author{
Mirabel C. Rezende \\ Instituto de Aeronátuica e Espaço, Divisão de Materiais
}

\begin{abstract}
Resumo: Técnicas que contribuem para melhorar a qualidade dos compósitos produzidos por laminação manual e cura em autoclave e/ou visando à redução no custo de processamento têm sido intensamente pesquisadas. Uma das maneiras de se obter esse ganho de produtividade é eliminar operações de usinagem da borda por meio da técnica de fabricação de laminados com bordas moldadas. Neste trabalho é apresentada uma revisão da tecnologia de fabricação de peças estruturais de compósitos poliméricos avançados, com ênfase na produção de laminados com bordas moldadas. Exemplos deste tipo de acabamento são mostrados utilizando laminados cruzados simétricos $[(0,90) / 0]_{\mathrm{s}}$ e $[(0,90) / 90]_{\mathrm{s}}$ fabricados com fita unidirecional contínua e tecido bidirecional de carbono, pré-impregnados com resina epóxi. O arranjo de fibras e resina na região da borda livre de todos os corpos-de-prova foi analisado usando um microscópio óptico. Foi observado que as fibras longitudinais $\left(\right.$ a $\left.0^{\circ}\right)$ podem se mover lateralmente na direção da borda moldada sob ação da pressão aplicada durante a cura. Bolsas de resina pura podem ser formadas nessa região dependendo da seqüência de empilhamento do laminado.
\end{abstract}

Palavras-chave: Laminados, compósitos poliméricos avançados, bordas moldadas, métodos de fabricação.

\section{Processing of advanced structural polymeric composite laminates with molded edges}

Abstract: Manufacturing techniques that improve the quality and/or reduce the cost of advanced composites structures produced by vacuum bag and cure in autoclave have been intensely investigated. One way to obtain a gain in productivity is to produce laminates with molded edges. This work presents a literature review of the fabrication process of structural parts of advanced polymeric composites, with emphasis in the manufacturing of laminates with molded edges. As an example of this type of edge finishing, symmetric cross ply laminates $[(0,90) / 0]_{\mathrm{s}}$ and $[(0,90) / 90]_{\mathrm{s}}$ were manufactured with pre-impregnated unidirectional tape and fabric. The arrangement of fibers and resin near the free edge of all specimens were analyzed using an optical microscope. It was observed that longitudinal fibers in the laminate (fibers at $0^{\circ}$ ) may move laterally towards the molded edge under the action of the pressure applied during cure. Pockets of pure resin may be formed at this region depending on the laminate stacking sequence.

Keywords: Laminates, advanced composites, prepreg, molded edge, fabrication.

\section{Introdução}

A combinação de baixa massa específica com valores elevados de resistência e rigidez, que os compósitos poliméricos avançados proporcionam, permite que essa classe de materiais seja empregada nas indústrias aeronáutica e espacial em substituição aos materiais metálicos tradicionais ${ }^{[1-6]}$. Componentes estruturais de aeronaves para fins civil e militar, tais como: flapes, leme, carenagens, empenagens, naceles, aileron, tanques de combustível, profundor e cone de cauda, entre outros, que anteriormente eram fabricados em ligas de alumínio, titânio e aços especiais, estão hoje sendo fabricados na sua grande maioria em estruturas 


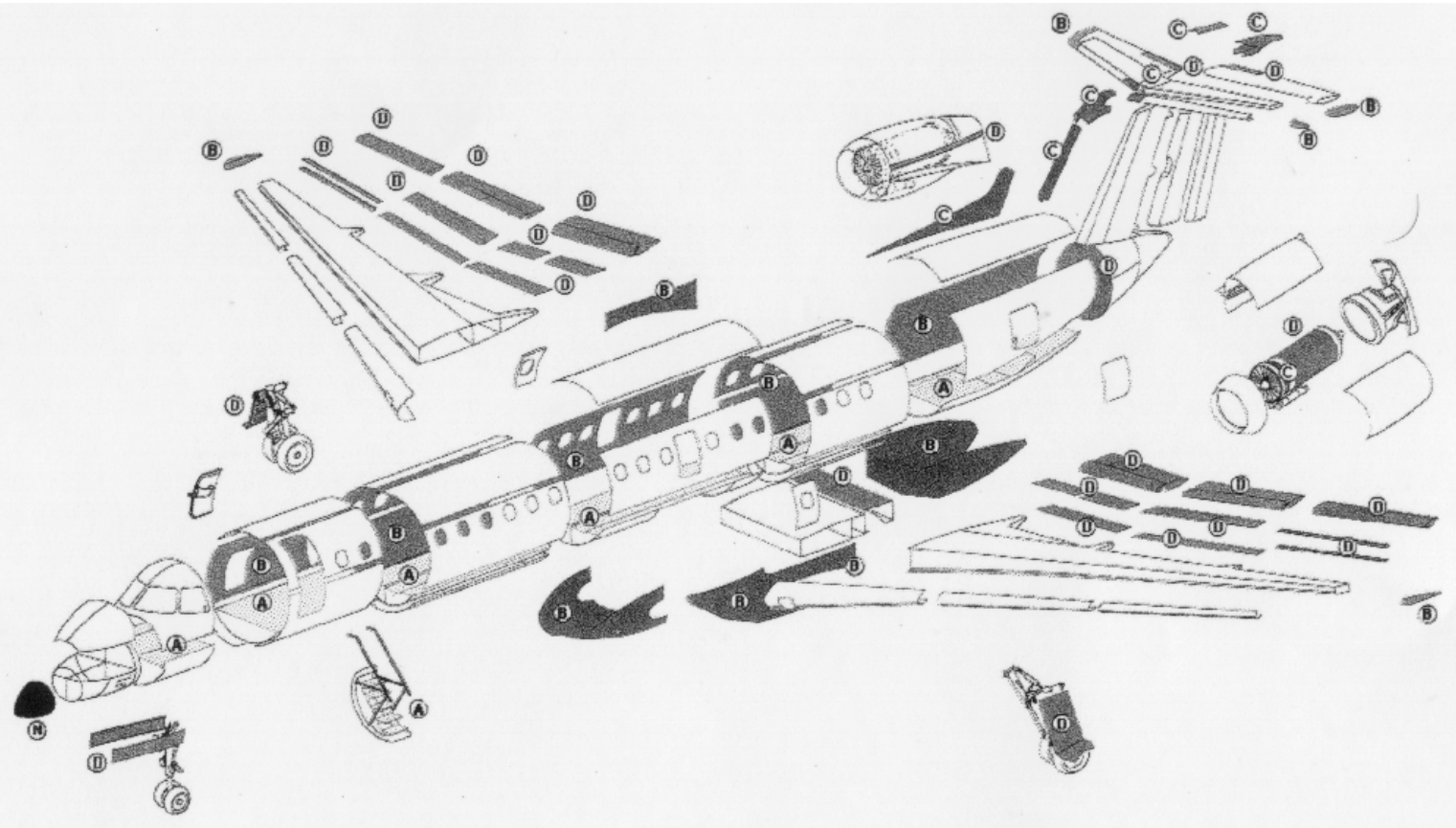

Nota:
(1) Radone - Fibra de Vidro
A

B
Painéis Sanduiche (Fibra de Carbono / Colméia Nomex) ou (Fibra de Vidro / Colméia Nomex)

Fibra de Vidro ou (Fibra de Vidro + Colméia Nomex)

Fibra de Carbono ou (Fibra de Carbono ou Colméia Nomex) ou (Fibras de Carbono + Aramida)

Fibra de Aramida ou (Fibras de Aramida + Vidro) ou (Fibras de Aramida + Vidro + Colméia Nomex)

Figura 1. Vista explodida da aeronave EMB-145, mostrando as partes fabricadas em compósitos poliméricos avançados (Cortesia da EMBRAER).

laminadas de materiais pré-impregnados de compósitos poliméricos avançados ${ }^{[7-10]}$, como mostra a Figura 1. Os compósitos poliméricos avançados podem oferecer aos componentes estruturais elevada resistência à fadiga e à corrosão, baixa condutividade térmica, isolação acústica e térmica e facilidade de obtenção de geometrias complexas, assegurando-lhes maior performance em serviço ${ }^{[11,12]}$.

Com a constante evolução tecnológica que o processamento e as matérias-primas precursoras dos compósitos poliméricos avançados vêm apresentando, novos espaços em aplicações não aeronáuticas estão sendo conquistados, contribuindo simultaneamente, para o crescimento do interesse industrial em desenvolver e produzir produtos mais leves com elevados padrões da qualidade e de resistência estrutura ${ }^{[13-24]}$. Um desenvolvimento bem sucedido será obtido quando se equilibra a eficácia do método de fabricação com a redução do seu custo e o elevado padrão da qualida- de do produto. Neste caso, maior atenção deve ser dada aos métodos de fabricação automatizados, pois esses podem garantir as grandes escalas de produção exigidas nos outros setores não aeronáuticos ${ }^{[8,25-28]}$.

O material pré-impregnado é uma matéria-prima intermediária para a produção de compósito polimérico avançado onde a resina e o endurecedor combinam-se com a fibra por meio de processamento automático e controlado, dando consistência ao produto. Considerando-se que o pré-impregnado está parcialmente curado, a aplicação de temperatura, vácuo e pressão durante o processo de cura do laminado é necessária para acelerar a obtenção da estrutura final ${ }^{[1,12]}$. Historicamente na produção da indústria aeronáutica, a maioria dos componentes é fabricada pelo método convencional de corte e laminação manual das camadas do material pré-impregnado, sobre um molde devidamente preparado, seguido da cura em autoclave. O laminado é fabricado com excesso de material sen- 
do que o recorte e acabamento da borda livre é realizado por técnicas de usinagem mecânica convencional. Este método exige mão-de-obra intensiva e especializada para obtenção de produtos de alta qualidade.

Visando eliminar as operações de recorte e acabamento da borda livre, sem penalizar o peso e o custo da estrutura, foi recentemente proposta por Almeida e Cândido uma técnica para fabricar laminados com bordas livres moldadas ${ }^{[29]}$. Esta técnica consiste em empilhar as camadas do material préimpregnado sobre a superfície polida de um molde com contornos fechados, nas dimensões geométricas exatas do laminado, prescindindo, assim, do acabamento ${ }^{[30-32]}$. Logo, se a preferência for para trabalhar com o método de laminação, a fabricação de compósitos com bordas livres moldadas é uma alternativa que merece ser estudada e analisada em termos de custo e benefício.

Assim sendo, este trabalho tem como objetivo apresentar uma revisão da tecnologia de fabricação de peças estruturais de compósitos poliméricos avançados com ênfase na produção de laminados com bordas moldadas. Em particular será feita uma análise qualitativa do procedimento utilizado na fabricação de duas famílias de laminados cruzados simétricos $[(0,90) / 0)]_{\mathrm{s}} \mathrm{e}[(0,90) /$ $90]_{\mathrm{S}}$ de material pré-impregnado de carbono/epóxi, com bordas retas moldadas ou usinadas em retífica. São descritos os aspectos básicos de preparação da infra-estrutura necessária para o processamento de laminação do material, a cura dos laminados e a inspeção final do produto. A análise microestrutural realizada mostra o comportamento das fibras e da resina durante a cura na autoclave e sua relação com a qualidade do acabamento obtido por esta técnica de fabricação, especialmente na região da borda moldada.

\section{Processamento de Compósitos Poliméricos Avançados}

\section{Escolha dos Materiais}

Uma das particularidades dos compósitos poliméricos avançados é que, ao se fabricar um laminado, fabrica-se, simultaneamente, o material final e o produto. Neste caso, a matéria-prima, ou seja, o pré-impregnado, é fornecida no estado semi-acabado, pronta para o processamento, pois os reforços fibrosos são previamente impregnados com a matriz polimérica desejada parcialmente curada, ou seja, no estágio B. Por conseqüência, o pré-impregnado é fornecido e deve ser mantido selado em bolsas de papel alumínio e plástico à base de polipropileno para ser armazenado à temperatura de $-18^{\circ} \mathrm{C}$ ou inferiores, de modo a desacelerar o processo de cura da resina, como também minimizar a perda do solvente residual ${ }^{[33,35,39]}$. $\mathrm{Na}$ indústria de compósitos esta matéria-prima é comumente chamada de "prepreg"[33-36].

Atualmente, o material mais utilizado para a fabricação de laminados de componentes estruturais aeronáuticos é o pré-impregnado de carbono/epóxi. A fibra de carbono utilizada é de alta resistência e, normalmente, é tratada para maior compatibilidade química com o sistema de resina epóxi utilizado ${ }^{[33,37,38]}$.

\section{Propriedades Mecânicas dos Prepregs Utilizados}

As principais propriedades de engenharia dos préimpregnados de fita unidirecional contínua e tecido bidirecional são obtidas por ensaios de carregamento estático em tração e compressão uniaxial e cisalhamento no plano e interlaminar, à temperatura ambiente e de serviço dos laminados fabricados, conforme os métodos clássicos padronizados pelas normas ASTM. Dada a anisotropia desse tipo de material há a necessidade de medir as suas propriedades de tração e compressão em pelo menos duas direções ${ }^{[1,40]}$. Além disso, para se ter maior representatividade estatística de dados, todas as camadas devem ser cortadas do mesmo lote de material pré-impregnado.

A Tabela 1 mostra os valores nominais típicos na temperatura ambiente das propriedades mecânicas do prepreg de carbono/epóxi F-584 da Hexcel Composites e a medida da espessura nominal da camada individual[ ${ }^{[30]}$.

\section{Sala com Ambiente Controlado}

O processamento do material pré-impregnado na fabricação dos laminados aeronáuticos deve ser realizado em uma sala climatizada, adequadamente limpa, com a temperatura controlada na faixa de $21 \pm 3^{\circ} \mathrm{C}$ e a umidade relativa do ar de $60 \%$ no máximo. Esse recinto deve ficar isolado de outras áreas de fabricação para evitar a entrada de poeira, mantendo as portas sempre fechadas, abrindo somente quando necessário e no mínimo tempo possível, de modo a conservar o ambiente climatizado e com o ar sempre limpo ${ }^{[30,39]}$. Para prevenir a contaminação, os desmoldantes devem ser armazenados em salas separadas. 
Tabela 1. Propriedades Nominais Típicas dos Pré-impregnados de Carbono/Epóxi F-584.

\begin{tabular}{lccc}
\hline \multicolumn{1}{c}{ Propriedades Mecânicas } & $\begin{array}{c}\text { Fita } \\
\text { Unidirecional }\end{array}$ & $\begin{array}{c}\text { Tecido } \\
\text { Bidirecional }\end{array}$ & $\begin{array}{c}\text { Norma } \\
\text { ASTM }\end{array}$ \\
\hline Módulo Longitudinal, $\mathrm{E}_{1}(\mathrm{GPa})$ & 130 & 65 & $\mathrm{D} 3039$ \\
Módulo Transversal, $\mathrm{E}_{2}(\mathrm{GPa})$ & 2 & 65 & $\mathrm{D} 3039$ \\
Módulo de Cisalhamento, $\mathrm{G}_{12}(\mathrm{GPa})$ & 6 & 5 & $\mathrm{D} 4255$ \\
Quociente de Poisson, $\mathrm{v}_{12}(\mathrm{GPa})$ & 0,27 & 0,05 & $\mathrm{D} 3039$ \\
Resistência à Tração Longitudinal, $\mathrm{X}_{\mathrm{T}}(\mathrm{MPa})$ & 1721 & 680 & $\mathrm{D} 3039$ \\
Resistência à Tração Transversal, $\mathrm{Y}_{\mathrm{t}}(\mathrm{MPa})$ & 43 & 680 & $\mathrm{D} 3039$ \\
Resistência à Compressão Longitudinal, $\mathrm{X}_{\mathrm{c}}(\mathrm{MPa})$ & 703 & 548 & $\mathrm{D} 3410$ \\
Resistência à Compressão Transversal, $\mathrm{Y}_{\mathrm{c}}(\mathrm{MPa})$ & 133 & 548 & $\mathrm{D} 3410$ \\
Resistência ao Cisalhamento no Plano, $\mathrm{S}_{12}(\mathrm{MPa})$ & 88 & 122 & $\mathrm{D} 4255$ \\
Resistência ao Cisalhamento Interlaminar, $\mathrm{S}_{13}(\mathrm{MPa})$ & 84 & 70 & $\mathrm{D} 2344$ \\
Massa Específica, $\rho\left(\mathrm{kg} / \mathrm{mm}^{3} \mathrm{x} 10^{-5}\right)$ & 0,155 & 0,157 & $\mathrm{D} 3171$ \\
Espessura Nominal da Camada, $\mathrm{t}_{\text {nom }}(\mathrm{mm})$ & 0,18 & 0,35 & 1,22 \\
Massa Específica da Resina $\left(\mathrm{g} / \mathrm{cm}^{3}\right)$ & 1,22 & 1,77 & \\
Massa Específica da Fibra de Carbono $\left(\mathrm{g} / \mathrm{cm}^{3}\right)$ & 1,77 & &
\end{tabular}

Devem-se tomar os cuidados necessários para impedir que ocorra a contaminação do pré-impregnado por partículas e impurezas do ar durante o seu processamento, o que causaria a degradação das propriedades físicas, impossibilitando a sua utilização em aplicações de responsabilidade estrutural.

Logicamente, este rigor será reduzido para produtos de menor responsabilidade estrutural.

\section{Ferramental de Moldagem}

O ferramental deve ter superfícies polidas em retífica para proporcionar aos laminados excelente acabamento superficial. Também todas as arestas, pinos cônicos e insertos devem ser arredondados e polidos para evitar danos na bolsa de vácuo durante ação da pressão na cura ${ }^{[29]}$. Além disso, o ferramental deve ser rígido para evitar empenamento e com baixa capacidade térmica para permitir taxas de aquecimento mais elevadas ${ }^{[41]}$.

Um dos materiais sugeridos para a fabricação de ferramental é o aço SAE 1020. Este material possui baixo coeficiente de expansão térmica na temperatura de cura do compósito, assegurando aos laminados precisão e estabilidade dimensional, podendo ser usinado com tolerâncias apertadas ${ }^{[41,42]}$. Geralmente, a espessura de $12,7 \mathrm{~mm}$ é suficiente para dar a rigidez necessária na usinagem da chapa de aço. Ferramentas em compósitos também são utilizadas para estruturas mais complexas, que apresentam grandes curvaturas.

\section{Corte das Camadas}

Na sala climatizada as bobinas dos materiais préimpregnados devem ser removidas do freezer para o ambiente controlado, permanecendo seladas nas bolsas protetoras durante o período necessário para que atinjam o equilíbrio térmico. Este procedimento previne a condensação de umidade sobre os pré-impregnados. Uma vez atingida a temperatura ambiente, a bobina de pré-impregnado está em condições de ser cortada em camadas ${ }^{[39,42]}$.

O corte pode ser realizado manual ou mecanicamente ${ }^{[43]}$. O corte manual é feito com o auxílio de um estilete guiado por um molde metálico na forma final da camada a ser laminada, tomando-se o cuidado para não danificar ou contaminar as fibras. Após o corte, essas camadas são identificadas, embaladas e seladas em bolsas plásticas de polipropileno, formando conjuntos que são armazenados novamente em freezer para a posterior operação de laminação.

\section{Laminação das Camadas}

A laminação das camadas obedece às seqüências de empilhamento particularizadas nas famílias de 
laminados simétricos, que compõem a matriz de testes ou o produto a ser obtido.

$\mathrm{Na}$ obtenção de bons laminados é imprescindível compactar as camadas com um rolo para eliminar saliências ou rugas, evitar a retenção de ar ou o desalinhamento das fibras ${ }^{[39]}$. Também, todo cuidado é tomado para evitar que objetos estranhos ao compósito fiquem retidos entre as camadas, pois causam a rejeição do laminado ${ }^{[30]}$.

\section{Bolsa de Vácuo}

A aplicação de vácuo nos laminados é uma operação necessária para se obter a compactação uniforme das camadas e simultaneamente extrair voláteis, solvente e umidade, evitando a formação de porosidades ou vazios e remover o excesso de resina para evitar a presença de bolsas de resina pura ${ }^{[33,44,45]}$. Em razão disto, é necessário confeccionar uma bolsa de filme plástico flexível cujo tipo de material escolhido seja compatível com a temperatura e o tempo de cura dos laminados e a espessura do filme seja resistente à pressão.

Na montagem dessa bolsa, além do filme plástico, é necessário utilizar materiais auxiliares, tais como, tecido separador, tecido absorvedor do excesso de resina, tecido canalizador para a remoção do ar, chapa de compactação, tecido superficial removível, bico para vácuo e fita selante para vedar a bolsa em todo contorno do ferramental, como, também, para formar uma barreira de controle do excesso de resina, conforme esquema mostrado na Figura 2.

O tecido separador é um desmoldante que fica posicionado sobre a última camada do laminado, para evitar que o tecido absorvedor do excesso de resina adira ao tecido superficial removível ou à

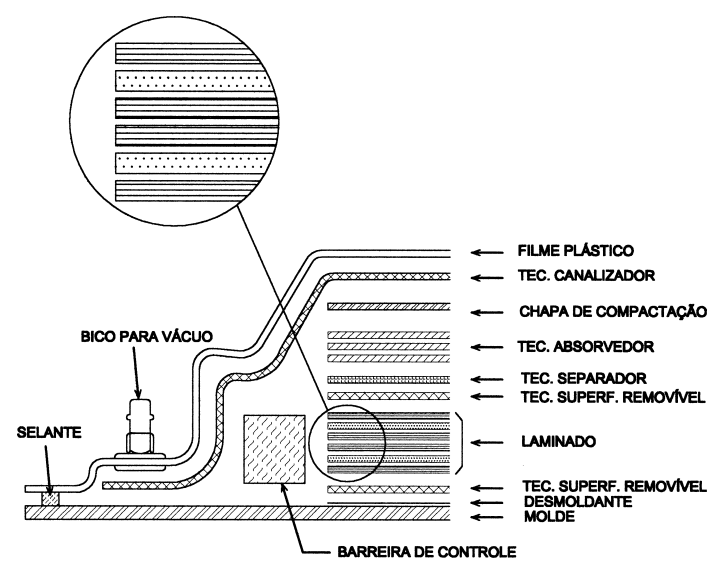

Figura 2. Representação esquemática da bolsa de vácuo superfície não acabada do produto. Este tecido é feito de fibra de vidro impregnada com silicone ou teflon e de malha porosa para permitir que o excesso de resina e os voláteis removidos dos laminados fluam livremente através dele. A camada de tecido superficial removível é moldada sobre a superfície do laminado para proporcionar uma superfície quimicamente limpa para colagem, quando este é removido ${ }^{[39,42]}$.

As camadas de tecido absorvedor são posicionadas cobrindo toda a área do laminado, de modo que a absorção do excesso de resina seja uniforme. Sobre estas camadas é colocada uma chapa fina de aço inox com quatro furos de $1,0 \mathrm{~mm}$ de diâmetro, distribuídos regularmente. Esta chapa auxilia na compactação uniforme e melhora o acabamento superficial do lado do laminado que não está em contato com o ferramental de moldagem. Para cobrir completamente esta montagem, é colocada uma camada de tecido canalizador, visando à remoção do ar e dos gases resultantes da cura. A característica principal deste tecido é assegurar que o fluxo dos gases ocorra normalmente, mesmo sob a ação da pressão aplicada durante a cura ${ }^{[30,42,46]}$.

Em seguida, é posicionada a base do bico para vácuo e a fita selante no contorno da borda do ferramental de moldagem, de modo a fechar o filme plástico e formar a bolsa. Finalizando, o bico é acoplado à base, que por sua vez está posicionada no interior da bolsa. Este é conectado à mangueira de sucção e aplicado o vácuo de $0,078 \mathrm{MPa}$ para verificar a existência ou não de vazamentos na bolsa antes do processo de cura dos laminados. O vácuo é mantido até os laminados seguirem para a cura em autoclave ${ }^{[30,42,46]}$.

\section{Cura em Autoclave}

A excelente qualidade de fabricação, que se exige dos laminados estruturais aeronáuticos, é conferida pelo controle do teor adequado de resina e pela presença mínima de vazios. Um nível de $2 \%$ de vazios é tipicamente considerado como aceitável ${ }^{[12,47]}$. Entretanto, o nível aceitável pode ser diferente dependendo do material, aplicação e tipo de carregamento ${ }^{[47]}$. Os tipos de descontinuidades aceitáveis depende da aplicação do produto. Em alguns casos, a aceitação é embasada em normas estabelecidas pelo fabricante e/ ou pelo usuário do compósito.

As melhores condições de processamento são obtidas pela pressurização durante a realização do ciclo 


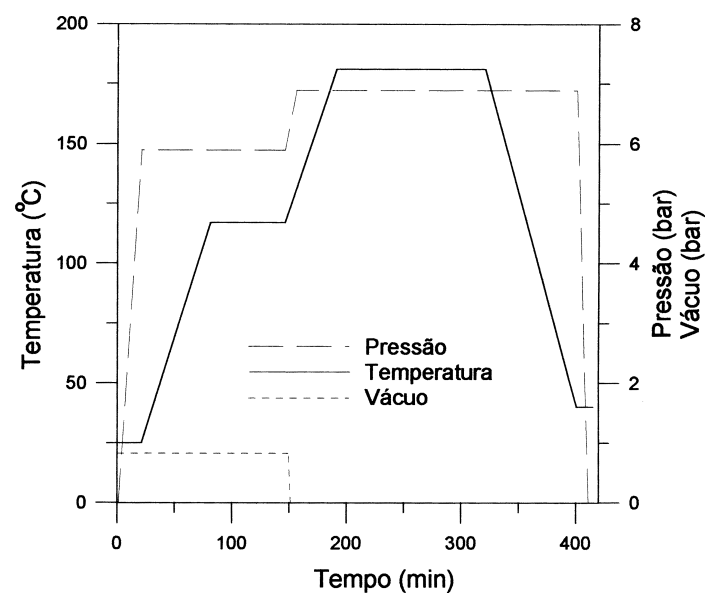

Figura 3. Ciclo de cura dos laminados de pré-impregnados F-584 da Hexcel Composites.

de cura pelo método mais comum utilizado, que é o processo em autoclave ${ }^{[46-48]}$. Esse equipamento é um vaso de pressão que permite a aplicação combinada de calor, pressão e vácuo durante a consolidação das reações de reticulação da resina, convertendo-a em um termorrígido ${ }^{[42,44,46,50]}$. A Figura 3 mostra esquematicamente o gráfico do ciclo de cura sugerido para a resina F-584, da empresa Hexcel Composites.

Durante o ciclo de aquecimento ocorrem mudanças no estado físico da resina, sendo a mais importante a que ocorre na região de gel. Uma vez ultrapassada esta região o fluxo da resina é prejudicado, pois esta já se encontra na região viscoelástica ${ }^{[46]}$. Logo, a aplicação da pressão deve ser feita antes desta região para promover a compactação dos laminados e determinar o ciclo de cura ótimo ${ }^{[51,52]}$. A aplicação do vácuo visa à eliminação de vazios ${ }^{[46]}$.

\section{Acabamento da Borda Livre}

Esta é a operação que conclui o processo de fabricação dos produtos de compósitos poliméricos avançados por laminação a vácuo e cura em autoclave. Nos laminados com bordas moldadas esta operação é rápida e muito simples, consistindo em se fazer uma suave rebarbação manual ao longo da superfície da borda, para remover o excesso de resina que fluiu durante $o$ ciclo de cura, tomando-se o cuidado para não descaracterizar o contorno geométrico da borda livre $^{[30,45]}$. No caso dos laminados com bordas usinadas usados neste trabalho o contorno é produzido por uma operação de corte seguida de acabamento em retífica $^{[42,53]}$. Uma vez acabados, os laminados são enviados para a inspeção final da qualidade do produto ${ }^{[30,45]}$.

\section{Inspeção da Qualidade}

A qualidade dos laminados é verificada pela avaliação da quantidade de porosidade, bolsas de resina pura, trincas e delaminações que podem ser geradas durante a cura e o acabamento. A técnica de ultra-som por transmissão por coluna de água ou com acoplamento manual e por pulso-eco é a mais utilizada para a detecção dessas descontinuidades ${ }^{[37,54-57]}$.

Estas técnicas permitem fazer uma varredura dos laminados podendo dar ou não informações de profundidade. A técnica atualmente mais utilizada para os laminados sólidos é a de transmissão por coluna de água. $\mathrm{O}$ equipamento possui um emissor ultrasônico, por meio do qual os sinais sônicos são emitidos através de uma coluna de água de diâmetro variável entre 3 e $6 \mathrm{~mm}$, dependendo da freqüência utilizada. Esse equipamento possui um receptor especular conectado ao emissor, onde são coletados os níveis de energia originados da colimação dos jatos de água com o material. Um fator muito importante a ser considerado na operação de inspeção é o alinhamento dos jatos de água do equipamento utilizado. Estes são ajustados de forma manual ou mecânica até formar um disco de água laminar perpendicular à linha dos jatos.

Durante a operação de varredura, os dados de atenuação são registrados em um sistema de aquisição de dados do equipamento, na forma de níveis de voltagem e impressos em um gráfico de diferentes cores, que identificam as áreas com descontinuidades no laminado.

\section{Experimental}

O pré-impregnado utilizado na fabricação dos laminados foi fornecido pela empresa Hexcel Composites na forma de bobinas de fita unidirecional contínua, código T 2L 190 12" F584-3 e tecido bidirecional estilo eight-harness satin weave (8-HS), código F 3L 584 42" F584-102. As letras T e F significam Tape e Fabric, 2L e 3L indicam ter 12000 e 3000 filamentos/cabo, 190 e 584 definem a gramatura, 12" e 42" a largura das bobinas e F584 o sistema de resina epóxi modificada ${ }^{[58-61]}$. No tecido 8-HS um fio do urdume passa sobre sete fios da trama e por baixo do oitavo, conferindo maior flexibilidade durante o seu manuseio no processo de conformação de superfícies curvas $^{[62,63]}$.

As camadas foram cortadas na sala climatizada 
nas dimensões desejadas de $(360$ x 300) mm conforme a orientação desejada das fibras, mantendo a tolerância de alinhamento dos reforços de aproximadamente $1^{\circ}$, utilizando-se um esquadro. Essas camadas foram empilhadas obedecendo à seqüência de orientação das fibras $[(0,90) / 0]_{\mathrm{S}}$ e $[(0,90) / 90]_{\mathrm{S}}$ formando duas placas de tecido bidirecional combinado com fita unidirecional para cada compósito.

De uma placa de cada família foram recortados manualmente cinco amostras de $(350 \times 50) \mathrm{mm}$, que foram acomodadas nas cavidades da ferramenta, de modo que a primeira camada ficasse totalmente em contato com a superfície do molde. Esta ferramenta foi preparada com desmoldante adequado ao sistema de resina (Release All75, da Airtech) fora da sala climatizada.

Outras duas placas foram laminadas, uma de cada compósito, sobre um molde plano devidamente preparado com desmoldante, para a posterior obtenção das amostras com bordas usinadas. Em seguida, foi preparada a bolsa de vácuo nos laminados conforme o esquema mostrado na Figura 2 , verificada a não existência de vazamentos e iniciada a cura.

O procedimento de cura foi realizado em uma autoclave, cujas condições de operação utilizadas para o sistema de resina F-584 são apresentadas na Figura 3. Pode ser observado que neste ciclo de cura a temperatura atinge o valor máximo de $181^{\circ} \mathrm{C}$ com $0,69 \mathrm{MPa}$ (6,9 bar) de pressão e vácuo agindo a $0,083 \mathrm{MPa}(0,83 \mathrm{bar})$, com taxa de aquecimento e resfriamento de $2,5^{\circ} \mathrm{C} / \mathrm{min}$.

Esta atividade foi monitorada e avaliada por termopares, manômetros e vacuômetro. Durante esta etapa do processamento não foi registrado nenhum desvio em relação ao esquema do ciclo apresentado. Após a cura todos os laminados foram desmoldados e inspecionados visualmente. O método de digestão em ácido nítrico, ASTM D 3171, também foi utilizado para verificar o conteúdo médio de resina em peso e o volume de fibras.

A operação de acabamento da borda foi realizada manualmente por rebarbação do excesso de resina da borda moldada e mecanicamente, em retífica plana horizontal, nas amostras com bordas usinadas. Em seguida, todos os laminados foram inspecionados por ultra-som pela técnica de transmissão por coluna de água utilizando um transdutor de $5 \mathrm{MHz}$ com o jato de água de $3 \mathrm{~mm}$ de diâmetro.

\section{Resultados e Discussão}

A qualidade dos laminados processados foi assegurada pela quantidade de tecidos absorvedores colocada na bolsa de vácuo e a correta execução do procedimento de cura da resina. No material pré-impregnado não curado, tanto na fita unidirecional contínua como no tecido bidirecional, o conteúdo de resina em peso certificado pelo fabricante é de $41 \pm 3 \%$. Já para os laminados curados, aplicando-se o método da digestão em ácido nítrico conforme norma ASTM D 3171, o conteúdo médio de resina em peso encontrado foi de $27,7 \%$ e o volume de fibras foi de $64,7 \%(\mathrm{v} / \mathrm{v})$. Por esta técnica também foram quantificados o conteúdo de vazios de $0,51 \%(\mathrm{v} / \mathrm{v})$ no interior dos laminados e a massa específica dos compósitos de $1,58 \mathrm{~g} / \mathrm{cm}^{3}$. Estes valores certificam que os laminados são de boa qualidade.

A análise microestrutural dos laminados foi realizada pela técnica de microscopia óptica, utilizandose amostras previamente embutidas em resina poliéster, tendo as superfícies planas e polidas para avaliar como ocorreu a compactação das camadas e a distribuição das fibras e resina no interior dos laminados, especialmente na região da borda moldada ${ }^{[38,63]}$.

A fotomicrografia mostrada na Figura 4 é representativa do padrão da qualidade obtido na compactação das camadas dos laminados fabricados, utilizando o processo de cura em autoclave apresentado. Os efeitos combinados da temperatura, pressão e vácuo foram fundamentais na obtenção dos laminados com espessura uniforme e isentos de defeitos, onde os espaços foram completamente preenchidos pela resina, como já havia sido assegurado pela inspeção ultra-sônica. Esta característica é atribuída à relação do fluxo da resina com a viscosidade e o tempo de gelificação (gel). Por sua vez, o tempo de gel é um dado muito importante na definição dos melhores parâmetros de processamento, visando obter compósitos com a qualidade exigida na aplicação final.

A análise das Figuras 5 e 6 mostra que a configuração do arranjo de fibras/resina, formado na região da borda moldada, é resultado da seqüência de empilhamento das camadas e da movimentação lateral das fibras posicionadas a $0^{\circ}$ no laminado (vista transversal da fotomicrografia) sob a ação da pressão externa, que atua durante a cura. Essa pressão é aplicada quando a resina ainda está no estado líquido. 


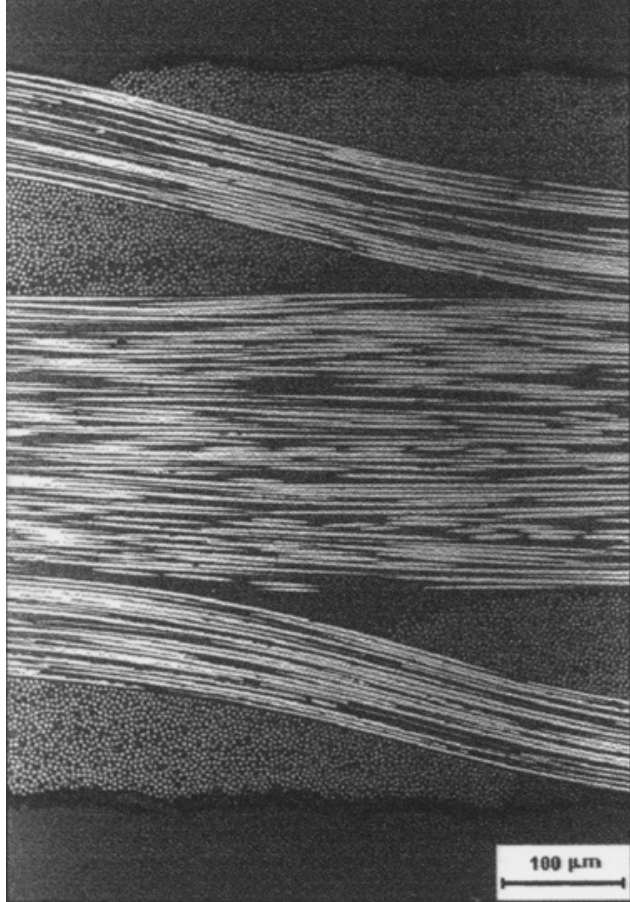

Figura 4. Seção transversal do laminado $[(0,90) / 90]_{\mathrm{S}}$

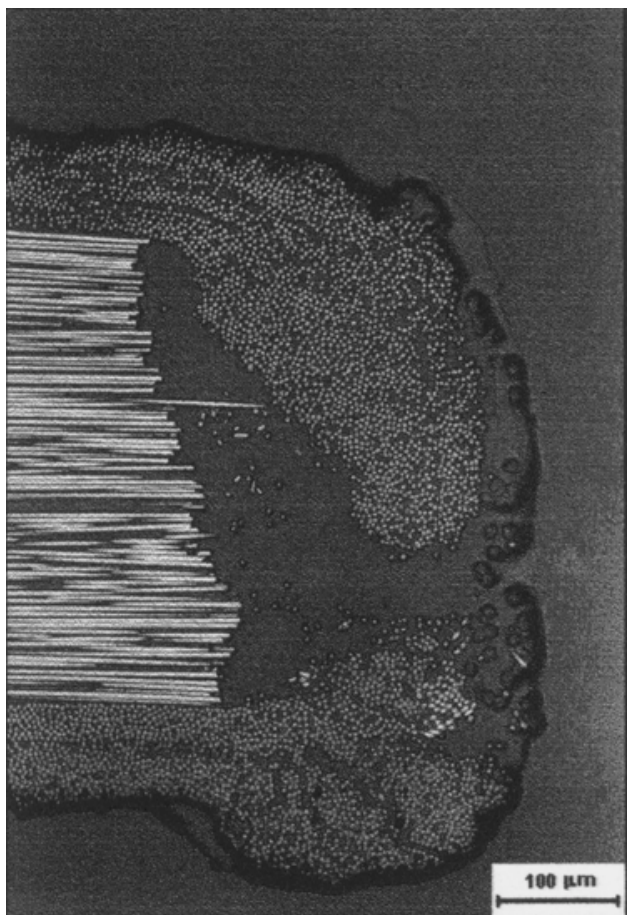

Figura 6. Seção transversal da borda moldada do laminado $[(0,90) / 90]_{\mathrm{S}}$

Com o incremento da pressão, determinada quantidade de fibras a $0^{\circ}$ se movimenta para a borda, até que um número suficiente se distribui em um arranjo dependente da pressão aplicada.

Como resultado observa-se na Figura 5 que uma região rica em resina, reforçada somente por fibras a $0^{\circ}$,

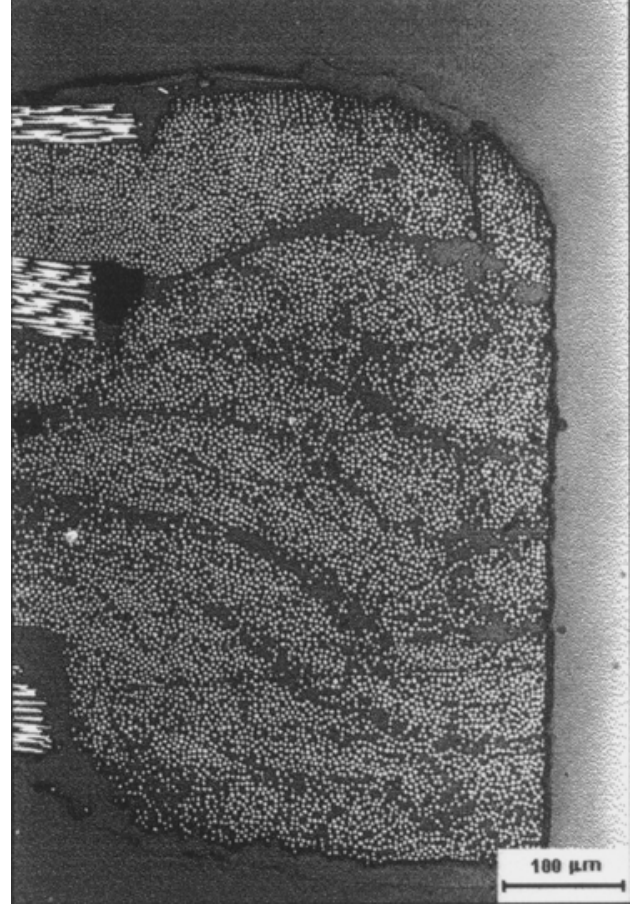

Figura 5. Seção transversal da borda moldada do laminado $[(0,90) / 0]_{\mathrm{S}}$

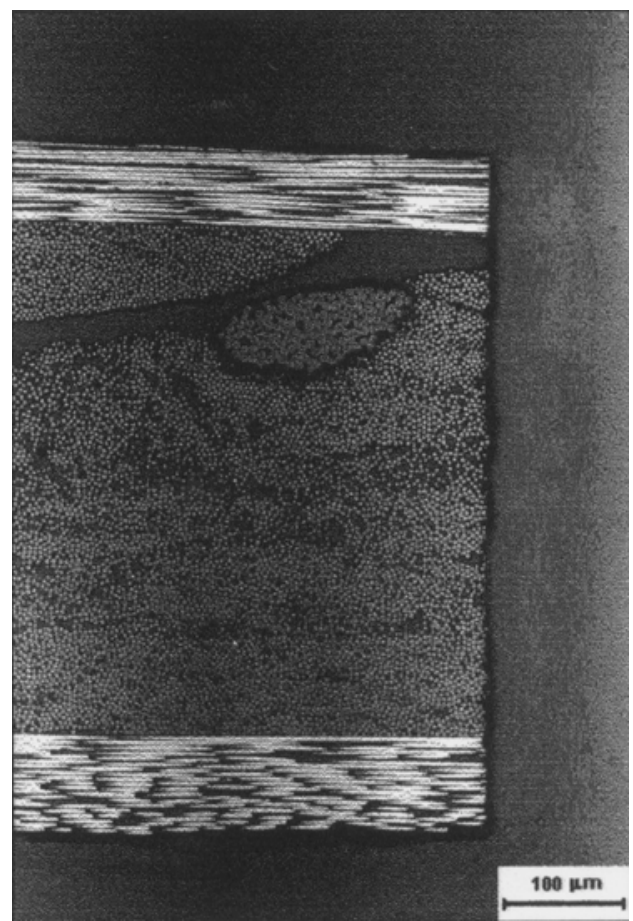

Figura 7. Seção transversal da borda retificada do laminado $[(0,90) / 0]_{\mathrm{S}}$

é formada na borda livre do laminado. Isto se deve ao fato do compósito $[(0,90) / 0]_{\mathrm{s}}$ possuir um maior volume de fibras a $0^{\circ}$, que durante a aplicação da pressão de cura se desloca em direção às paredes laterais do molde, distribuindo-se em uma região proporcionalmente homogênea de resina, formando a borda moldada. 
Por outro lado, no compósito $[(0,90) / 90]_{\mathrm{s}}$ (Figura 6), a borda moldada é tipicamente formada por uma bolsa de resina pura reforçada por fibras a $0^{\circ}$, distribuídas ao seu redor. Isto é explicado pelo menor volume de fibras a $0^{\circ}$ que este compósito possui e que, por sua vez, está concentrado nas camadas externas do tecido bidirecional. Sob a ação da pressão de cura, estas fibras têm a tendência de se moverem para a borda livre. Entretanto, este movimento é praticamente neutralizado pelo fluxo do excesso de resina, que flui das camadas interiores posicionadas a $90^{\circ}$, formando um arranjo de fibras/resina com uma bolsa de resina relativamente grande na região central da borda moldada.

Nestes dois tipos de laminados a região de borda formada se expandiu por uma distância de aproximadamente $0,3 \mathrm{~mm}$, configurando geometricamente a borda moldada dos compósitos fabricados. Todavia, a seqüência de empilhamento das camadas e o volume de fibras a $0^{\circ}$ dos laminados, são fatores determinantes na formação destes arranjos de fibras/ resina da borda moldada. Observando-se estas considerações, pode-se ter laminados com borda moldada apresentando bolsas de resina ou vazios ou então formando arranjos relativamente homogêneos de resina reforçada por fibras a $0^{\circ}$ ao longo de toda a extensão da borda moldada.

Este tipo de acabamento de borda é diferente de uma borda livre usinada em retífica, que confere à superfície da borda livre um acabamento especular homogêneo, como pode ser observado na Figura 7. A qualidade de acabamento superficial de borda livre, observada nesta figura, é representativa de todas as amostras de laminados com bordas usinadas em retífica.

O feixe de fibras de maior diâmetro que aparece no canto superior direito da Figura 7 é um feixe de fibras de vidro, que marca a direção dos filamentos do tecido de carbono.

Deve-se enfatizar que a presença de bolsas de resina pura na região da borda livre pode causar uma redução significativa na resistência do laminado ${ }^{[29-32]}$. Este problema pode ser minimizado escolhendo-se uma seqüência de empilhamento que não favoreça o aparecimento de bolsas de resina.

\section{Conclusões}

Atualmente, grandes esforços em pesquisas são dirigidos à produção de laminados de alto desempe- nho estrutural a baixo custo. Esses fatores são afetados pela escolha do material, condições do ambiente de laminação, características do ferramental, metodologia de fabricação e técnica de inspeção. Um procedimento criterioso como descrito no item Processamento de Compósitos Poliméricos Avançados é fundamental para atender aos requisitos de alta qualidade ao custo mais baixo possível.

A fabricação de laminados de material pré-impregnado com bordas moldadas é uma alternativa promissora para a produção em escala industrial de compósitos poliméricos avançados por laminação a vácuo e cura em autoclave. Esta técnica elimina as operações de acabamento da borda do laminado pelo método de usinagem convencional e permite maior aproveitamento do material, o que resulta em redução do custo de fabricação e elimina a rejeição de peças por delaminação de borda devido ao corte.

Por outro lado, a fabricação de compósitos com bordas moldadas apresenta, como desvantagem, a formação de bolsas de resina pura na região da borda, podendo causar uma redução na resistência do laminado. Este problema pode ser minimizado escolhendo-se uma seqüência de empilhamento que não favoreça o aparecimento de bolsas de resina.

\section{Agradecimentos}

Os autores agradecem à FAPESP pelo apoio financeiro recebido, à EMBRAER e à Divisão de Materiais do IAE pelo suporte na parte experimental da pesquisa e à empresa Hexcel Composites pelo fornecimento do material pré-impregnado.

\section{Referências Bibliográficas}

1. Bratukhin, A. G. \& Bogolyubov, V. S. - "Composite Manufacturing Technology”, Chapman \& Hall, London (1995).

2. Hull, D. - “Materiales Compuestos”, Editorial Reverté, S. A., Barcelona (1987).

3. Epstein, G. \& Ruth, S. - SAMPE Journal 1, p. 24 (1996).

4. Robinson, M. J.; Charette, R. O.\& Leonard, B. G. SAMPE Quartely, 2, p.26 (1991).

5. McConnell, V. P. - Advanced Composites, 4, p. 26 (1991). 
6. McConnell, V. P. - Advanced Composites, 1, p. 32 (1990).

7. Gay, D. - “Matériaux Composites”, Hermès, Paris (1989).

8. Schwartz, M. M. - “Composite Materials Handbook”, McGraw-Hill, New York (1984).

9. Stover, D. - Advanced Composites, 5, p. 30 (1991).

10. McConnell, V. P. - Advanced Composites, 4, p. 27 (1990).

11. Tan, S. C. - "Stress Concentrations in Laminated Composites”, Technomic Publishing Co., Inc., Lancaster (1994)

12. Strong, A. B. - "Fundamentals of Composites Manufacturing: Materials, Methods, and Applications”, SME, Dearbon (1989).

13. McConnell, V. P. - Advanced Composites, 2, p. 31 (1992).

14. Klein, A. J. - Advanced Composites, 6, p. 36 (1988).

15. Allbee, N. - Advanced Composites, 4, p. 36 (1988).

16. Stover, D. - Advanced Composites, 3, p. 47 (1991).

17. Barbero, E. \& GangaRao, H. V. S. - SAMPE Journal, 6, p. 9 (1991).

18. Barbero, E. \& GangaRao, H. V. S. - SAMPE Journal, 1, p. 9 (1992).

19. Berman, D. W. - SAMPE Journal, 4, p.21 (1992).

20. Loud, S. - SAMPE Journal, 1, p. 30 (1996).

21. Barnes, F. J. - SAMPE Journal, 2, p. 12 (1996).

22. Davis, S. - SAMPE Journal, 3, p. 30 (1996).

23. Martin, R. H. - SAMPE Journal, 6, p. 37 (1996).

24. Sultan, M. - SAMPE Journal, 3, p. 10 (1997).

25. Klein, A. J. - Advanced Composites, 1, p. 44 (1989).

26. Leonard, L. - Advanced Composites, 5, p. 49 (1989).

27. Krolewski, S. \& Gutowski, T. - "Economic Comparison of Advanced Composite Fabrication Technologies", in: 34 th International SAMPE Symposium, p. 329, may (1989).

28. Foley, M. F. - SAMPE Quartely, 2, p. 61 (1991).

29. Almeida, S. F. M. \& Cândido, G. M. - Composite Structures, 25, p. 287 (1993).
30. Cândido, G. M. - "Efeito do Tipo de Acabamento da Borda Livre na Resistência à Tração de Laminados de Carbono/Epóxi”, Tese de Mestrado, Instituto Tecnológico de Aeronáutica, Brasil (1993).

31. Cândido, G. M.; Almeida, S. F. M. \& Mazza, F. "Técnicas de Fabricação para Laminados com Bordas Moldadas Resistentes à Delaminação”, in: Anais do XIV Congresso Brasileiro de Engenharia Mecânica - CD-ROM, UNESP Bauru SP, dez (1997).

32. Cândido, G. M.; Rezende, M. C. \& Almeida,S. F. M. - "Influência do Efeito Higrotérmico na Resistência de Laminados Cruzados de Carbono/Epóxi com Bordas Moldadas, in: Anais do $13^{\circ}$.Congresso Brasileiro de Engenharia e Ciências dos Materiais - CD-ROM, Curitiba - PR, dez (1998).

33. Delmonte, J. - "Technology of Carbon and Graphite Fiber Composites”, Robert E. Krieger Publishing Co., Inc., Malabar, (1981).

34. Ellis, B. - "Chemistry and Technology of Epoxy Resins”, Chapman \& Hall, London (1993).

35. Hancox, N. L. \& Mayer, R. M. - "Design Data for Reinforced Plastics”, Chapman \& Hall, London (1994).

36. Putnam, J. W.; Hayes, B. S. \& Seferis, J. C. - Journal of Advanced Materials, 3, p. 47 (1996).

37. Mallic, P. K. - "Fiber-Reinforced CompositesMaterials, Manufacturing, and Design”, Marcel Dekker, Inc. New York (1993).

38. Chou, T. W. - "Materials Science and TechnologyStructure and Properties of Composites”, v. 13, VCH Publishers Inc., New York (1993).

39. Lee, S. M. - “International Encyclopedia of Composites”, v. 4, VCH Publishers Inc., New York (1990).

40. Adams, D. F. - "Test Methods for Composite Materials", Technomic Publishing Co., Inc., Lancaster

41. Morena, J. J. - “Advanced Composite Mold Making”, Van Nostrand Reinhold Company Inc., New York (1988).

42. Lubin, G. - “Handbook of Composite”, Van Nostrand Reinhold Co., Inc., New York (1982).

43. Wang, Y.; Hoa, S. V. \& Osman, M. O.M. - Journal of Reinforced Plastics and Composites, 12, p.1119 (1998). 
44. Bader, M. G.; Smith, W.; Isham, A. B.; Rolston, J. A. \& Metzner, A.B. - "Delaware Composites Design Encyclopedia-Processing and Fabrication Technology”, v. 3, Technomic Publishing Co., Inc. Lancaster (1990).

45. British Plastics - "Handbook of Polymer Composites for Engineers", Woodhead Publisng Ltd, Cambridge (1994).

46. Carlson, L. A. \& Pipes, R. B. - "Experimental Characterization of Advanced Composites Materials", Technomic Publishing Co., In. Lancaster (1997).

47. Almeida, S. F. M. \& Nogueira Neto, Z. S. - Composite Structures, 28, p. 130 (1994).

48. Dave, R; Kardos, J. L.; Choi, S. J. \& Dudukovic', M. P. - "Autoclave vs. Non-Autoclave Composite Processing”, in: 32 nd International SAMPE Symposium, p.325, april (1987).

49. Wu, H. T. \& Joseph, B. - SAMPE Journal, 6, p. 39 (1990).

50. Dave, R. S.; Mallow, A,; Kardos, J. L. \& Dudukovic', M. P. - SAMPE Journal, 3, p.31 (1990).

51. Kim, T. W. \& Jim, E. J. - "Compaction Behavior of Thick Composite Laminates During Cure", in: 34 th International SAMPE Symposium, p. 15, may (1989).

52. Joseph, B.; Hanratty, F. W. \& Kardos J. L. - Journal of Composite Material, 8, p. 1000 (1995).

53. Schwarts, M. M. - SAMPE Journal, 2, p.18 (1996).
54. Ashbee, K. H. G. - "Fundamental Principles of Fiber Reinforced Composites", Technomic Publishing Co., In. Lancaster (1993).

55. Kaczmarek, H. - Journal of Composite Materials, 1, p. 59 (1995).

56. Scarponi, C. \& Briotti, G. - Journal of Reinforced Plastics and Composites, 9, p. 768 (1997).

57. Gros, X. E.; Ogi, K. \& Takahashi, K. - Journal of Reinforced Plastics and Composites, 5, p. 389 (1998).

58. Hexcel "Advanced Composite Reinforcements", Hexcel Composites, Pleasanton, Califórnia (1989).

59. Hexcel - "Fabric Handbook", Hexcel Composites, Pleasanton, Califórnia (1990).

60. Hexcel - "Resin Systems for Advanced Composites - Resin Matrix Selector"- Hexcel Composites, Pleasanton, Califórnia (1988).

61. Hexcel - "Resin Systems for Advanced Composites F584"- Hexcel Composites, Pleasanton Pleasanton, Califórnia (1990).

62. Zweben, C. ; Hahn, H. T. \& Chou, T. W. - "Delaware Composites Design Encyclpedia-Mechanical Behavior and Properties of Composite Materials", v. 1, Technomic Publishing Co., Inc. Lancaster (1989).

63. Klein, A. J. - Advanced Materials \& Processes, 3, p. 40, (1986).

64. Clements, L. L. - "Fiber Composite Materials"in: Metals Handbook, v. 9, Metals Park, ASM (1985).

Recebido: 01/06/99

Aprovado: 14/01/00 